\title{
Dosimetric Comparison of Intensity-Modulated Radiotherapy and Volumetric Arc Therapy for Rectal Cancer
}

\author{
(D) Sedenay OSKEROĞLU KAPLAN,' (D) Halil AKBÖRÜ, ${ }^{2}$ (D) Yunus SARALI, ${ }^{3}$ (D) Süleyman ALTIN, ${ }^{2}$ \\ (1) Mustafa ÜNSAL ${ }^{4}$
}

'Department of Radiation Oncology, Mehmet Akif İnan Training and Research Hospital, Şanlıurfa-Turkey

${ }^{2}$ Department of Radiation Oncology, Okmeydanı Training and Research Hospital, İstanbul-Turkey

${ }^{3}$ Department of Medical Physics, Okmeydanı Training and Research Hospital, İstanbul-Turkey

${ }^{4}$ Department of Radiation Oncology, Avrupa Şafak Hospital, İstanbul-Turkey

\begin{abstract}
OBJECTIVE
The aim of the present study is the dosimetric comparison of intensity-modulated radiation therapy and volumetric arc therapy (VMAT) that are currently applied in the preoperative radiotherapy of locally advanced rectal cancer.
\end{abstract}

\section{METHODS}

Ten patients with locally advanced rectal cancer were recontoured according to defined protocol on computed tomography simulation that was previously scanned. Dosimetric comparison was performed for each patient with 7 and 9 fields intensity-modulated radiation therapy and VMAT. Compared dosimetric parameters were determined as doses of organs at risk, the total duration of treatment, target coverage, conformity index, homogeneity index, and the total monitor unit (MU).

\section{RESULTS}

All plans provided comparable dosimetric parameters for target volumes. Arc plans demonstrated a statistically significant benefit with lower doses on $\mathrm{V}_{15}$ and $\mathrm{D}_{\text {mean }}$ of the small bowel than intensity-modulated radiation therapy. Arc plans were obviously superior relating to measured volumes of the whole body, and plans with 7 field had the worst results. In addition, the reduction in total treatment time by approximately $60 \%$ was achieved in arc plans.

\section{CONCLUSION}

VMAT with short treatment duration and low MUs can be considered as providing a more comfortable and qualified treatment.

Keywords: Intensity-modulated radiotherapy; preoperative chemoradiotherapy; rectal cancer; volumetric arc therapy. Copyright $\odot$ 2019, Turkish Society for Radiation Oncology

\section{Introduction}

Neoadjuvant chemoradiotherapy (CRT) has become the standard therapy to obtain the desired results in patients with locally advanced (T3/T4) and lymph node involve- ment (stage II-III) rectal cancer with regard to local control and cure. Many studies have shown the superiority of preoperative radiotherapy in reducing the risk of local recurrence and toxicity compared with postoperative radiotherapy.[1-3] However, acute and chronic
Received: October 08, 2018

Accepted: December 11, 2018

Online: May 29, 2019

Accessible online at:

www.onkder.org

OPEN ACCESS This work is licensed under a Creative Commons

Attribution-NonCommercial 4.0 International License.
Dr. Sedenay OSKEROĞLU KAPLAN

Radyasyon Onkolojisi Anabilim Dalı,

Mehmet Akif İnan Eğitim ve Araştırma Hastanesi,

Şanlıurfa-Turkey

E-mail: oskarum@gmail.com 
intestinal toxicities caused by preoperative treatment are still the most important causes of morbidity.[4]

The relationship between specific dose-volume constraints and organ toxicity has been known.[5-6] The small bowel is a radiosensitive organ as acute radiation enteritis occurs in many patients undergoing radiotherapy for rectal cancer. Many studies showed that the incidence of both acute and late effects is directly related to the maximum dose and total volume of irradiated bowel.[7,8] Grade 3-4 acute toxicity was reported in up to $23 \%$ of patients treated with preoperative radiotherapy with concurrent chemotherapy, increasing to $37 \%$ with doses $>50$ Gy to the pelvis. $[9,10]$

Accordingly, highly conformal radiation therapy planning and delivery techniques, such as intensitymodulated radiotherapy (IMRT) and volumetric arc therapy (VMAT), that allows for a reduction of high doses to organs at risk (OARs), without compromising target coverage, are being investigated. Therefore, there are several studies comparing the inverse planning system with different IMRT and VMAT techniques, and the clinical implications of the results are still unclear. $[11,12]$ Thus, the aim of the present study was to compare the OARs sparing without compromising the target coverage among 7 and 9 fields IMRT and doublearc VMAT prospectively.

\section{Materials and Methods}

\section{Patient Groups}

Ten patients ( 5 women and 5 men) with locally advanced rectal cancer treated with the indication of preoperative CRT/radiotherapy in Okmeydanı Training and Research Hospital between 2012 and 2015 were observed. The median age of the patients was 55 (minmax 33-69) years. Tumor length varied between 2 and $10 \mathrm{~cm}$, with median lengths of $6 \mathrm{~cm}$. All patients had stage III $(\mathrm{cT} 3 \mathrm{~N}+)$ disease.

\section{Monitoring, Target Volume Determination, and Dose Prescription}

All patients were stabilized in a prone position using a carbon-fiber belly board. The planning computed tomography (CT) scanned at a slice thickness of $3 \mathrm{~mm}$ was transferred to the Eclipse 10.0 treatment planning system. Positron emission tomography-CT and/ or magnetic resonance imaging images recorded were matched using fusion algorithms to determine target volume. Treatment volumes were recalibrated according to the Radiation Therapy Oncology Group (RTOG) consensus of conformal contouring atlas for anorectal cancer published online in 2008.[13] Fullness or empty bladder was not implemented. The OARs were bladder, right and left femur heads, and small bowel. The dose to the OARs at least complied with the following constraints: bladder $\geq 65$ Gy in $\leq 50 \%$ volume, small bowel (peritoneal cavity) $\geq 45$ Gy in $\leq 195 \mathrm{cc}$ volume, and femur heads $\geq 40$ Gy in $\leq 10 \%$ volume.

\section{Planning Techniques and Objectives}

Planning target volumes (PTV1 and PTV2) were planned using the Eclipse 10.0 treatment planning system on the Trilogy linac and Millennium 120 MLC system using the simultaneous single boost method. The prescribed doses were 45 Gy to the PTV2 and 50.4 Gy simultaneous to the PTV1 in 25 fractions. Three plans were performed for each patient, including 7 field IMRT (IMRT7), 9 field IMRT (IMRT9), and double-arc VMAT (ARC). The maximum dose rate was optimized to 600 $\mathrm{MU} / \mathrm{min}$. $6 \mathrm{MV}$ photons were used in all plans.

Plan optimization is defined as taking $100 \%$ of the prescription dose covered by at least $95 \%$ of the PTV. The values of $\mathrm{D}_{98 \%}$ (dose received by $98 \%$ of the PTV) and $\mathrm{D}_{2 \%}$ (dose received by $2 \%$ of the PTV) for PTV were determined as the minimum and maximum doses $\left(\mathrm{D}_{\text {mean }}\right.$ and $\left.\mathrm{D}_{\text {max }}\right)$ according to the International Commission on Radiation Units and Measurements-83. The conformity of the plans was evaluated with a conformity index (CI) defined as the ratio of the target volume receiving $95 \%$ of the prescribed dose divided by the total volume receiving that dose level. The homogeneity of the plans was measured with regard to the homogeneity index $(\mathrm{HI})$, which was expressed as $\left(\mathrm{D}_{2 \%}{ }^{-}\right.$ $\left.\mathrm{D}_{98 \%}\right) / \mathrm{D}_{50 \%}$. The Eclipse system was not able to calculate the estimated treatment time per fraction. Therefore, monitor unit (MU) values were used in VMAT plans to compare treatment times ("beam on"). The duration of treatment was determined by the ratio of the total MU to the maximum dose rate (MU/dose rate). In IMRT plans, "beam on" times were obtained from the system. Plan Quality Assurance (QA) was performed for total treatment periods. Data were obtained using dose-volume histograms (DVHs). Anisotropic Analytical Algorithm (version 10.0.028) was used as the planning algorithm, and Dose Volume Optimizer (version 10.0.028) was used for optimization algorithm.

\section{IMRT Plans}

The IMRT plans were calculated using seven fixed gantry angles $\left(0^{\circ}, 52^{\circ}, 104^{\circ}, 154^{\circ}, 208^{\circ}, 260^{\circ}\right.$, and $\left.312^{\circ}\right)$ and nine fixed gantry angles $\left(0^{\circ}, 41^{\circ}, 82^{\circ}, 123^{\circ}, 164^{\circ}\right.$, $205^{\circ}$, and $328^{\circ}$ ). 


\section{VMAT Plans}

Each plan with double arc consisted of two complete arcs set from $181^{\circ}$ to $179^{\circ}$ and from $179^{\circ}$ to $181^{\circ}$ (clockwise and counterclockwise), respectively. The collimator angles were defined as $30^{\circ}$ and $330^{\circ}$ for all plans.

\section{Organ at Risk}

OAR for each plan was evaluated by the following: $\mathrm{V}_{<12}$ (volume receiving $<12 \mathrm{~Gy}$ ), $\mathrm{V}_{15}, \mathrm{D}_{\text {min }}$, and $\mathrm{D}_{\max }$ for small bowel; $\mathrm{V}_{30}, \mathrm{~V}_{40}$, and $\mathrm{D}_{\text {mean }}$ for bladder; $\mathrm{D}_{15}, \mathrm{~V}_{30}$, $\mathrm{D}_{\text {max }}$, and $\mathrm{D}_{\text {mean }}$ for each femoral head; and $\mathrm{V}_{10}, \mathrm{~V}_{20}, \mathrm{~V}_{30}$, and $V_{40}$ for normal tissue that excluded PTV2 from the whole body (NTV).

\section{Statistical Analysis}

All dosimetric results from different irradiation techniques were compared with each other. Repeated mea- sures analysis of variance was used for comparison of plans. Bonferroni correction was used for post hoc analysis. Intraclass correlation coefficient was used to determine the correlation between measurements. A p-value of $<0.05$ was considered statistically significant.

\section{Results}

The statistical dosimetric evaluation and comparison of the three planning techniques are listed in Table 1.

\section{Target Coverage and Dose Distribution}

The mean volume of the PTV was $1452.9 \pm 115.1 \mathrm{cc}$, the minimum was $286.9 \mathrm{cc}$, and the maximum was 603.6 cc. For PTV1, IMRT9 achieved better HI than IMRT7 and ARC $(\mathrm{p}=0.026)$. Although $\mathrm{D}_{98 \%}$ was higher for IMRT9 than for ARC ( $\mathrm{p}=0.001)$, there were no

Table 1 Dosimetric results for PTV and OARs

\begin{tabular}{|c|c|c|c|c|c|c|}
\hline & IMRT7 & IMRT9 & ARC & IMRT7 vs IMRT9 & IMRT7 vs ARC & IMRT9 vs ARC \\
\hline \multicolumn{7}{|c|}{ PTV1 volume (cc) } \\
\hline$D_{2 \%}(G y)$ & $52.93 \pm 0.16$ & $52.76 \pm 0.23$ & $52.88 \pm 0.18$ & $\mathrm{n}$ & $\mathrm{n}$ & $\mathrm{n}$ \\
\hline$D_{98 \%}(G y)$ & $50.10 \pm 0.19$ & $50.19 \pm 0.13$ & $49.97 \pm 0.11$ & $0.043^{*}$ & $\mathrm{n}$ & $0.020^{*}$ \\
\hline $\mathrm{D}_{\text {mean }}(\mathrm{Gy})$ & $51.54 \pm 0.12$ & $51.43 \pm 0.13$ & $51.52 \pm 0.12$ & $\mathrm{n}$ & $0.002^{* *}$ & $\mathrm{n}$ \\
\hline $\mathrm{V}_{95 \%}(\%)$ & $99.85 \pm 0.07$ & $99.93 \pm 0.05$ & $99.94 \pm 0.0$ & $\mathrm{n}$ & $\mathrm{n}$ & $\mathrm{n}$ \\
\hline $\mathrm{HI}$ & $0.054 \pm 0.005$ & $0.050 \pm 0.005$ & $0.056 \pm 0.003$ & $0.031^{*}$ & $\mathrm{n}$ & $\mathrm{n}$ \\
\hline $\mathrm{Cl}$ & $0.994 \pm 0.004$ & $1.013 \pm 0.034$ & $0.995 \pm 0.003$ & $\mathrm{n}$ & $0.024^{*}$ & $\mathrm{n}$ \\
\hline \multicolumn{7}{|c|}{ Small bowel volume (cc) } \\
\hline $\mathrm{V}_{<12}(\mathrm{cc})$ & $43.5 \pm 15.8$ & $44.0 \pm 9.4$ & $45.9 \pm 11.4$ & $\mathrm{n}$ & $\mathrm{n}$ & $\mathrm{n}$ \\
\hline $\mathrm{V}_{15}(\mathrm{cc})$ & $57.8 \pm 11.8$ & $50.8 \pm 8.9$ & $49.7 \pm 12.1$ & $\mathrm{n}$ & $0.030^{*}$ & $\mathrm{n}$ \\
\hline $\mathrm{V}_{30}(\mathrm{ccc})$ & $30.9 \pm 21.9$ & $17.5 \pm 7.4$ & $22.5 \pm 18$ & $\mathrm{n}$ & $\mathrm{n}$ & $\mathrm{n}$ \\
\hline$D_{\text {mean }}(G y)$ & $16.48 \pm 2.73$ & $16.93 \pm 2.97$ & $16.24 \pm 3.09$ & $\mathrm{n}$ & $\mathrm{n}$ & $0.035^{*}$ \\
\hline$D_{\max }(G y)$ & $48.21 \pm 2.40$ & $48.65 \pm 2.20$ & $49.04 \pm 1.96$ & $\mathrm{n}$ & $\mathrm{n}$ & $\mathrm{n}$ \\
\hline \multicolumn{7}{|c|}{ Bladder volume (cc) } \\
\hline $\mathrm{V}_{30}(\mathrm{ccc})$ & $35.2 \pm 6.8$ & $28.9 \pm 8.8$ & $26.3 \pm 3.8$ & $0.031^{*}$ & $0.020^{*}$ & $\mathrm{n}$ \\
\hline $\mathrm{V}_{40}(\mathrm{cc})$ & $13.2 \pm 4.3$ & $12.2 \pm 4.9$ & $11.2 \pm 3.6$ & $\mathrm{n}$ & $\mathrm{n}$ & $\mathrm{n}$ \\
\hline$D_{\text {mean }}(G y)$ & $27.52 \pm 1.84$ & $27.11 \pm 2.06$ & $24.83 \pm 1.82$ & $\mathrm{n}$ & $\mathrm{n}$ & $\mathrm{n}$ \\
\hline \multicolumn{7}{|c|}{ Femur heads R. volume (cc): $173.55 \pm 35.53$ (118.9-228.7) L. volume (cc) } \\
\hline R. $D_{\text {mean }}(G y)$ & $16.76 \pm 2.03$ & $13.17 \pm 0.92$ & $12.37 \pm 1.33$ & $0.001^{*}$ & $0.001^{*}$ & $\mathrm{n}$ \\
\hline R. $D_{\max }(G y)$ & $47.36 \pm 2.45$ & $45.07 \pm 2.86$ & $38.94 \pm 2.48$ & $\mathrm{n}$ & $0.001^{*}$ & $0.001^{*}$ \\
\hline R. $V_{30}(c c)$ & $11.1 \pm 3.4$ & $5.6 \pm 2.2$ & $2.4 \pm 0.7$ & $0.001^{*}$ & $0.001^{*}$ & $0.004^{*}$ \\
\hline R. $D_{15}(G y)$ & $28.26 \pm 2.16$ & $23.65 \pm 1.23$ & $22.42 \pm 1.22$ & $0.001^{*}$ & $0.001^{*}$ & $\mathrm{n}$ \\
\hline L. $D_{\text {mean }}(G y)$ & $15.77 \pm 2.14$ & $13.02 \pm 1.13$ & $11.90 \pm 1.13$ & $0.003^{*}$ & $0.001^{*}$ & $0.004^{*}$ \\
\hline L. D $D_{\max }(G y)$ & $47.94 \pm 1.93$ & $43.44 \pm 4.62$ & $38.73 \pm 3.24$ & $0.022^{*}$ & $0.001^{*}$ & $0.017^{*}$ \\
\hline L. $V_{30}(c c)$ & $9.1 \pm 3$ & $5.1 \pm 2.6$ & $2.5 \pm 1.2$ & $0.001^{*}$ & $0.001^{*}$ & $0.023^{*}$ \\
\hline L. $D_{15}(G y)$ & $26.65 \pm 1.67$ & $23.51 \pm 1.20$ & $22.54 \pm 0.87$ & $0.005^{*}$ & $0.001^{*}$ & $\mathrm{n}$ \\
\hline \multicolumn{7}{|c|}{ Normal tissue } \\
\hline $\mathrm{V}_{10}(\mathrm{cc})$ & $20.8 \pm 3.6$ & $21.8 \pm 4$ & $21.4 \pm 4.2$ & $0.004^{*}$ & $\mathrm{n}$ & $n$ \\
\hline $\mathrm{V}_{20}(\mathrm{cc})$ & $13.8 \pm 2.5$ & $11.9 \pm 2$ & $9.8 \pm 1.5$ & $0.001^{*}$ & $0.001^{*}$ & $0.001^{*}$ \\
\hline $\mathrm{V}_{30}(\mathrm{cc})$ & $5 \pm 0.7$ & $4.6 \pm 0.6$ & $3.9 \pm 0.5$ & $0.003^{*}$ & $0.001^{*}$ & $0.001^{*}$ \\
\hline $\mathrm{V}_{40}(\mathrm{cc})$ & $1.9 \pm 0.3$ & $1.9 \pm 0.3$ & $1.5 \pm 0.2$ & $\mathrm{n}$ & $0.001^{*}$ & $0.001^{*}$ \\
\hline
\end{tabular}

*Letter showed when comparison of both tested groups was significantly different $(p<0.05)$. $p$-value of $n$ means not statistically significant. 
significant differences between all plans on CI values $(\mathrm{p}=0.188)$. For PTV2, there was no difference for all the evaluated dosimetric parameters (Table 1). Dose distibutions of the three planning techniques for two patients in axial slices are shown in Fig. 1.

\section{Small Bowel and Bladder}

The mean volume of the small bowel was $822.2 \pm 340.7$ (430.2-1394.3) cc. There were no significant differences between all three plans on $\mathrm{V}_{<12}, \mathrm{~V}_{30}$, and $\mathrm{D}_{\max }$. However, $\mathrm{V}_{15}$ and $\mathrm{D}_{\text {mean }}$ were lower for ARC than for IMRT7 and
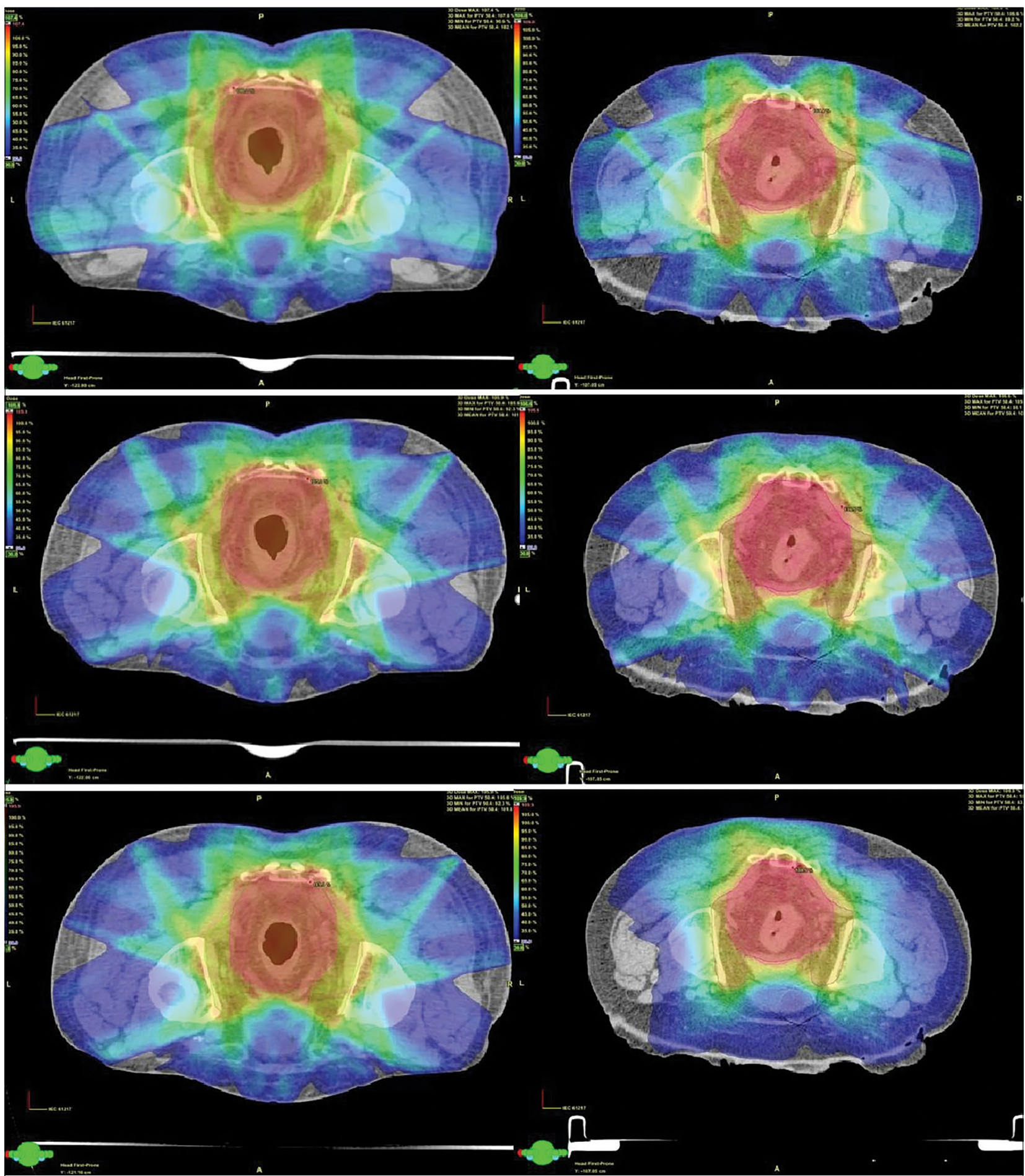

Fig. 1. In two patients, comparative dose distributions in IMRT7, IMRT9, and ARC in axial slices, respectively. 
IMRT9, respectively (ARC-IMRT7, p=0.030 and ARCIMRT9, $\mathrm{p}=0.035$ ). The volume of the bladder ranged from 62.6 to $517 \mathrm{cc}$ with a mean of $180.5 \pm 129.7 \mathrm{cc}$. The results for plans were comparable, but $\mathrm{V}_{30}$ was lower for IMRT7 than for both IMRT9 and ARC ( $\mathrm{p}=0.031$ and $\mathrm{p}=0.02$, respectively) (Table 1$)$.

\section{Femur Heads}

$\mathrm{V}_{40}$ for femur heads in each of three plans were excluded from the analysis because of detecting 40Gy on DVHs only linearly. In general, IMRT7 revealed the highest irradiated volumes, whereas IMRT9 and ARC could achieve comparably better results (Table 1).

\section{Normal Tissue}

$\mathrm{V}_{10}, \mathrm{~V}_{20}, \mathrm{~V}_{30}$, and $\mathrm{V}_{40}$ were evaluated for normal tissue that excluded PTV2 from the whole body (Table 1). The results for ARC were obviously superior relating to measured volumes, and IMRT7 plans had the worst results $($ ARC $<$ IMRT9 $<$ IMRT7).

\section{MUs and Durations of Treatment}

ARC plans had the lowest MU values, as expected $(p=0.01)$. There was no significant difference between the "beam on" times. However, when the total treatment time was considered, the superiority of ARC plans was observed according to data obtained with QA. The mean treatment periods were measured as $6.83+0.61 \mathrm{~min}$ in IMRT7, 8.21+0.74 min in IMRT9, and $3.09+0.31 \mathrm{~min}$ in ARC.

\section{Discussion}

Dosimetric benefits of IMRT and VMAT compared with three-dimensional conformal radiation therapy (3DRT) for preoperative treatment of rectal cancer are well established. These highly conformal radiation therapy planning and delivery techniques are based on the delivery of highly modulated dose fluence from multiple directions to limit high-dose volumes outside the treatment target. In this way, concave/convex isodose lines can be formed. This advantage means a reduction of high doses to OARs, creating lower acute and late toxicity expectations in clinical implication. There are several prospective studies using IMRT/VMAT for preoperative radiotherapy in rectal cancer. However, studies demonstrating clinical benefits are limited to phase I/II, and late toxicity data are few. The primary reason of using these technologies is to decrease acute and late toxicities for treatment tolerability and long-term quality of life. Radiation enteritis is the most common acute toxicity and occurs in many patients undergoing radiotherapy for rectal cancer. Grade 3-4 acute toxicity was reported in up to $23 \%$ of patients treated with preoperative CRT, increasing to $37 \%$ with doses $>50$ Gy. $[9,10]$ These data suggested that the small bowel volume receiving $15 \mathrm{~Gy}\left(\mathrm{~V}_{15}\right)$ is strongly associated with the degree of toxicity.[9] In addition, Robertson et al.[14] showed that $\mathrm{V}_{15}, \mathrm{~V}_{20}$, and $\mathrm{V}_{25}$ are associated with grade 3-4 diarrhea. Urbano et al.[15] reported a 64\% reduction in intestinal volume by $45-50$ Gy with IMRT compared with 3DRT in dosimetric analysis with patients with rectal cancer simulated in the prone position with a full bladder. In their study, three different IMRT schemes, as 5, 7, and 9 fields IMRT, were compared. Although the superiority of IMRT to 3DRT was shown, no significant difference was found in the effect of field count on the irradiated intestinal volume. In our study, although there was a decrease in the average $\mathrm{V}_{15}$ and $V_{30}$ values in IMRT9 compared with IMRT7 plans, there were no significant differences $\left(\mathrm{V}_{15}, \mathrm{p}=0.067\right.$ and $\left.\mathrm{V}_{30}, \mathrm{p}=0.107\right)$. ARC showed superior dosimetric results to IMRT7 on $\mathrm{V}_{15}$ and to IMRT9 on $\mathrm{D}_{\text {mean }}(\mathrm{p}=0.030$ and $\mathrm{p}=0.035$, respectively).

Moreover, there are several studies that have focused on treatment intensification by using different CRT regimens with the aim of limiting treatment-induced toxicity using IMRT.[16-19] RTOG 0822 that aimed a $12 \%$ reduction of grade 2 and over gastrointestinal (GI) toxicity with IMRT applied to neoadjuvant CRT (concurrent capecitabine $825 \mathrm{mg} / \mathrm{m}^{2}$ BID and 5 cycles of oxaliplatin $50 \mathrm{mg} / \mathrm{m}^{2}$ weekly) compared with RTOG 0247 applied with 3DRT showed a $51.5 \%$ rate of grade $\geq 2$ GI toxicity, which exceeded the observed rate of $40 \%$ in RTOG 0247.[19] Thus, the volume of the bowel receiving low-dose radiotherapy (e.g., 15 Gy) may be more important when using multi-agent chemotherapy, suggesting that low-dose constraints may need to be more compelling to produce a clinically optimal plan.

When the bladder tolerance doses are taken into account, dose prescriptions applied as preoperative for rectal cancer do not mean a significant risk for bladder toxicity. However, a volumetric or dosimetric threshold that can be associated with acute and late side effects in rectal cancer has not been established. Wolff et al. stated in 2011, in that compared proton, VMAT, IMRT, and 3DRT in patients with locally advanced rectal cancer, that only $\mathrm{V}_{40}$ volumes for bladder are statistically significantly higher in IMRT than in VMAT plans. [20] In the same year, a similar comparison was published by Cilla et al.[13] in which $\mathrm{V}_{15}, \mathrm{~V}_{30}, \mathrm{~V}_{40}, \mathrm{~V}_{50}, \mathrm{~V}_{55}$, and $\mathrm{D}_{\text {max }}$ analyses were performed for the bladder. How- 
ever, PTV1 was defined as 57.5 Gy. Although lower doses were obtained for the bladder in VMAT plans, no significant differences were found. In contrast with the literature, in our study for the bladder, $\mathrm{V}_{30}$ was significantly lower for IMRT7 than for IMRT9 $(p=0.031)$ and ARC $(p=0.02)$. These results could be caused by the used number of segments, different dose intensities on each fields, or prone position.

One of the important parts of pelvic radiotherapy with regard to late toxicity is the femur heads because of its function. Dose-response relationship is not known but is more frequent at higher doses of $40 \mathrm{~Gy}$. In the present study, ARC showed superior dosimetric results to IMRT. In addition, when IMRT plans are assessed within themselves, the superiority of IMRT9 plans is emphasized in all parameters. This may be due to the increased dose intensity compared with IMRT9 and because of non-coplanar beams $\left(104^{\circ}\right.$ and $\left.260^{\circ}\right)$ used in IMRT7.

Although IMRT and VMAT have defined dosimetric advantages, clinical reflections have yet to be demonstrated. Both techniques limit the high-dose areas obtained by normal tissues when compared with 3DRT, whereas the low-dose areas increase. This may lead to an increased risk of radiation-related cancer formation due to DNA mutations and carcinogenesis that increase in low- and moderate-dose values. As we assess the dosimetric comparison of normal tissue doses, $\mathrm{V}_{20}, \mathrm{~V}_{30}$, and $\mathrm{V}_{40}$ volumes were significantly lower in ARC plans (IMRT7>IMRT9>ARC). The number of field was only significant at lower doses (10 Gy), and $\mathrm{V}_{10}$ was better in IMRT7 than in IMRT9 plans ( $\mathrm{p}=0.004$ and $\mathrm{p}<0.01$, respectively).

The prolonged treatment increases the uncertainty due to the patient's movement, and it has been stated that IMRT was successful in reducing the volume of irradiated bowel with prone position in many studies.[21,22] Uncertainties during interfraction and intrafraction can cause the target dose to decrease below the desired dose due to sharp dose drops close to large target volumes at IMRT and VMAT. Considering all this, it can be said that VMAT's most important superiorities against IMRT are short duration of treatment and low MU values. VMAT resulted in a reduction of up to $60 \%$ in mean total treatment time (IMRT7 $6.83+0.61$ min, IMRT9 8.21+0.74 min, and ARC 3.09+0.31 min).

\section{Conclusion}

VMAT with short treatment duration and low MU values can be considered as providing a more comfortable and qualified treatment for patients with rectal cancer. The superiority obtained in OAR may not be meaningful because of the uncertainty in clinical manifestations. There is a need for phase III dosimetric studies to be performed with more patients and clinical observation.

Peer-review: Externally peer-reviewed.

Conflict of Interest: None declared.

Ethics Committee Approval: This study was conducted in accordance with local ethical rules.

Financial Support: None declared.

Authorship contributions: Concept - S.O.; Design - S.O., H.A.; Supervision - S.O., M.Ü.; Materials - S.O., H.A., S.A., Y.S.; Data collection \&/or processing - S.O., H.A.; Analysis and/or interpretation - S.O.; Literature search - S.O.; Writing - S.O.; Critical review - S.O., M.Ü.

\section{References}

1. Sauer R, Becker H, Hohenberger W, Rödel C, Wittekind C, Fietkau R, et al.; German Rectal Cancer Study Group. Preoperative versus postoperative chemoradiotherapy for rectal cancer. N Engl J Med 2004;351(17):1731-40.

2. Rödel C, Sauer R. Integration of novel agents into combined-modality treatment for rectal cancer patients. Strahlenther Onkol 2007;183(5):227-35.

3. Frykholm GJ, Glimelius B, Påhlman L. Preoperative or postoperative irradiation in adenocarcinoma of the rectum: final treatment results of a randomized trial and an evaluation of late secondary effects. Dis Colon Rectum 1993;36(6):564-72.

4. Kollmorgen CF, Meagher AP, Wolff BG, Pemberton $\mathrm{JH}$, Martenson JA, Illstrup DM. The long-term effect of adjuvant postoperative chemoradiotherapy for rectal carcinoma on bowel function. Ann Surg 1994;220(5):676-82.

5. Huang EH, Pollack A, Levy L, Starkschall G, Dong L, Rosen I, et al. Late rectal toxicity: dose-volume effects of conformal radiotherapy for prostate cancer. Int J Radiat Oncol Biol Phys 2002;54(5):1314-21. 6. Kupelian PA, Reddy CA, Carlson TP, Willoughby TR. Dose/volume relationship of late rectal bleeding after external beam radiotherapy for localized prostate cancer: absolute or relative rectal volume? Cancer J 2002;8(1):62-6.

7. Tho LM, Glegg M, Paterson J, Yap C, MacLeod A, McCabe M, et al. Acute small bowel toxicity and preoperative chemoradiotherapy for rectal cancer: investigating dose-volume relationships and role 
for inverse planning. Int J Radiat Oncol Biol Phys 2006;66(2):505-13.

8. Letschert JG, Lebesque JV, de Boer RW, Hart AA, Bartelink H. Dose-volume correlation in radiation-related late small-bowel complications: a clinical study. Radiother Oncol 1990;18(4):307-20.

9. Letschert JG, Lebesque JV, de Boer RW, Hart AA, Bartelink H. Dose-volume correlation in radiation-related late small-bowel complications: a clinical study. Radiother Oncol 1990;18(4):307-20.

10. Baglan KL, Frazier RC, Yan D, Huang RR, Martinez AA, Robertson JM. The dose-volume relationship of acute small bowel toxicity from concurrent 5-FUbased chemotherapy and radiation therapy for rectal cancer. Int J Radiat Oncol Biol Phys 2002;52(1):17683.

11. Kopp RW, Duff M, Catalfamo F, Shah D, Rajecki M, Ahmad K. VMAT vs. 7-field-IMRT: assessing the dosimetric parameters of prostate cancer treatment with a 292-patient sample. Med Dosim 2011;36(4):365-72.

12. Lawrie TA, Green JT, Beresford M, Wedlake L, Burden $\mathrm{S}$, Davidson SE, et al. Interventions to reduce acute and late adverse gastrointestinal effects of pelvic radiotherapy for primary pelvic cancers. Cochrane Database Syst Rev 2018;1:CD012529.

13. Myerson RJ, Garofalo MC, El Naqa I, Abrams RA, Apte A, Bosch WR, et al. Elective clinical target volumes for conformal therapy in anorectal cancer: a radiation therapyoncology group consensus panel contouring atlas. Int J Radiat Oncol Biol Phys 2009;74(3):824-30.

14. Guerrero Urbano MT, Henrys AJ, Adams EJ, Norman AR, Bedford JL, Harrington KJ, et al. Intensitymodulated radiotherapy in patients with locally advanced rectal cancer reduces volume of bowel treated to high dose levels. Int J Radiat Oncol Biol Phys 2006;65(3):907-16.

15. Robertson JM, Lockman D, Yan D, Wallace M. The dose-volume relationship of small bowel irradiation and acute grade 3 diarrhea during chemoradiotherapy for rectal cancer. Int J Radiat Oncol Biol Phys 2008;70(2):413-8.
16. Aristu JJ, Arbea L, Rodriguez J, Hernández-Lizoain JL, Sola JJ, Moreno M, et al. Phase I-II trial of concurrent capecitabine and oxaliplatin with preoperative intensity-modulated radiotherapy in patients with locally advanced rectal cancer. Int J Radiat Oncol Biol Phys 2008;71(3):748-55.

17. Arbea L, Martínez-Monge R, Díaz-González JA, Moreno M, Rodríguez J, Hernández JL, et al. Fourweek neoadjuvant intensity-modulated radiation therapy with concurrent capecitabine and oxaliplatin in locally advanced rectal cancer patients: a validation phase II trial. Int J Radiat Oncol Biol Phys 2012;83(2):587-93.

18.Zhu J, Gu W, Lian P, Sheng W, Cai G, Shi D, et al. A phase II trial of neoadjuvant IMRT-based chemoradiotherapy followed by one cycle of capecitabine for stage II/III rectal adenocarcinoma. Radiat Oncol 2013;8:130.

19. Hong TS, Moughan J, Garofalo MC, Bendell J, Berger AC, Oldenburg NB, et al. NRG Oncology Radiation Therapy Oncology Group 0822: A Phase 2 Study of Preoperative Chemoradiation Therapy Using Intensity Modulated Radiation Therapy in Combination With Capecitabine and Oxaliplatin for Patients With Locally Advanced Rectal Cancer. Int J Radiat Oncol Biol Phys 2015;93(1):29-36.

20. Wolff HA, Wagner DM, Conradi LC, Hennies S, Ghadimi M, Hess CF, et al. Irradiation with protons for the individualized treatment of patients with locally advanced rectal cancer: a planning study with clinical implications. Radiother Oncol 2012;102(1):30-7.

21. Stromberger C, Kom Y, Kawgan-Kagan M, Mensing T, Jahn U, Schneider A, et al. Intensity-modulated radiotherapy in patients with cervical cancer. An intra-individual comparison of prone and supine positioning. Radiat Oncol 2010;5:63.

22. Kim JY, Kim DY, Kim TH, Park SY, Lee SB, Shin $\mathrm{KH}$, et al. Intensity-modulated radiotherapy with a belly board for rectal cancer. Int J Colorectal Dis 2007;22(4):373-9. 